\title{
Qualitative Research in Information Systems: Time to be Subjective?
}

\section{Garcia}

Department of Social Psychology

London School of Economics and Political Science

London WC2A 2AE, England

Tel: 441719557695

Fax: 441719557565

E-mail: l.garcia@lse.ac.uk

\section{F. Quek}

Department of Information Systems

London School of Economics and Political Science

London WC2A 2AE, England

Tel: 441719557403

Fax: 441719557565

E-mail: f.k.quek@lse.ac.uk

\begin{abstract}
The starting point of a researcher's methodological choice within information systems is not so much a problem of how many methods we employ or if those are of a quantitative or a qualitative nature, but the ability to identify the philosophical and theoretical assumptions which leads to the choice of the appropriate methodology. In practice, despite the recognition of the virtues and the role of qualitative methods in information systems research, explicit institutional barriers and implicit functionalistic assumptions within the field have prevented much progress in their application. There is the danger in not recognizing the resulting side-effect where researchers use qualitative methods in a quantitative manner and pass it
\end{abstract}


off as qualitative research. Using qualitative methods implies allowing and acknowledging the subjectivity of the research process, which should be looked upon as a strength rather than as a weakness.

\section{INTRODUCTION}

This paper is the result of a seemingly impossible (ad)venture. It is a shared reflection about the use of one research paradigm within a field traditionally recognized for the use of another. It has been a common work based on two different cultural, academic and research backgrounds. As such, it has proven difficult and been plagued with obstacles, but at the same time, it has been full of relevant and highly illuminating discussions.

Although sometimes we have fallen into the trap of a "paradigm incommensurability" (Kuhn 1970), i.e., the impossibility of translating different paradigms into each other and assessing results of different paradigms (not only between the two authors, but also between the two topics covered in this conference: qualitative research and information systems), we have followed the tendency to regard at least some debate and discussion between various proponents of paradigms as possible (Reed 1985). We have worked in a metaphorical way,, transferring ideas and associations from one system or level of discourse to another. In this way, each system can be perceived anew from the point of view of the other. In the process, certain aspects have been illuminated whereas others have been shadowed.

We cover three main points in the paper. First, we stress the need for further critical awareness: reviewing what we are importing into the information systems field and why. Borrowing methods is not a simple task and, without critical awareness, runs the danger of the methods becoming stereotyped or distorted. Second, we consider that the direction promoted from the previous conference in 1990 on qualitative research about the quest for methodological pluralism and more alternative approaches, as well as the debate on quantitative versus qualitative methods, is somehow out of focus. The problem of applying research methods within information systems is not so much a problem of how many methods we employ or if those are of a quantitative or a qualitative nature, but rather to achieve a coherence over the whole research process. The starting point is to identify our philosophical and theoretical assumptions which will lead us to the choice of the appropriate methodology. Third, to comment that using qualitative methods implies allowing and acknowledging the subjectivity of the research process. The lack of this allowance leads researchers to use qualitative methods in a quantitative way. Methods developed mainly in a hermeneutic-dialectical school of meta-science are thus used from a logical-empirical perspective, and therefore the proposed paradigm shift is not fully achieved. From this standpoint, it is not appropriate to talk about coherence or rigour in the research process. 


\section{CRITICAL AWARENESS}

In the field of psychology, we learn how a particular philosophical commitment becomes taken for granted within the history of the discipline (Oppenheimer 1954; Danzinger 1979). Issues which should be opened to clarification and public debate are transformed into certainties, producing a cleavage between theory, method and their corresponding philosophical foundations. The consequence is the absence of a debate about philosophical foundations underlying the choice of methods and theory, to such an extent that few within the discipline are concerned with unearthing the assumptions guiding one alternative or another.

This absence of reflection is what Markova (1982) calls "the unjustified generalizations across different subjects." By overlooking the problems, conceptual frameworks or methods of research in different sciences - which are essentially different, crude generalizations - flourish unchallenged. If generalizations on such fundamental issues are possible, why not import successful models? The appropriateness of importing models is not even considered given the general lack of awareness regarding their presuppositions.

As Nissen, Klein and Hirschheim (1991) pointed out, "no field can avoid assumptions on the nature of its research approaches." However, in the domain of science, the importance of acknowledging the presuppositions on which every domain of human existence is based has great significance. Innocence with respect to our existing assumptions in scientific research is clearly associated with potential dangers (Markova 1982). The dangers are diverse but of the same kind. If a scientist is not aware of the foundations of the work, then the scientist is deprived of an occasion to reflect upon his or her actions, and tends to maintain the existing practice without the possibility of considering alternatives.

This seems to be the case regarding information systems. As a field, information systems is a relatively new one without a research tradition that it can claim to be its own. Its research frameworks and techniques are very much borrowed or imported from other disciplines (Bikson 1991). This reliance on a number of different areas for the development of a theoretical framework or research methods and the need to legitimize them has imported assumptions from those disciplines without a reflection upon the emergence of those assumptions or "upon the context within which attempts are made to operationalize them" (Preston 1991). There is no doubt that borrowing theoretical or methodological models from another discipline can lead to important innovations; however, there is the danger that, in doing so, the model becomes stereotyped or distorted.

As Guerreiro-Ramos (1981) suggests, there is an important distinction between the "displacement" and the "misplacement" of a model from its original discipline. The concept of system, for instance, was successfully displaced from its origins in cybernetics to study organizations. According to Guerreiro-Ramos, the misplacement of a model occurs when it is used inappropriately outside its discourse of origin, usually when there is no effort to understand the wider context where the model has been 
developed and therefore people only select that suit their concrete interests or way of thinking at a particular point in time. Thus, the misplacement occurs when the debates carried out about the different meanings and uses of the model during its historical evolution are not taken into account.

The past decade has seen the information systems field starting to undergo this kind of self-examination, raising philosophical issues associated with doing research in information systems and debating which philosophical traditions should guide work and which could serve as a legitimate basis for grounding research methods (Klein, Hirschheim and Nissen 1991; Preston 1991). There have been calls for a multidisciplinary approach and methodological pluralism, as well as rigor and relevance in research (Nissen, Klein and Hirschheim 1991).

Developing pluralism in information systems research has received increasing support. It is expected that the use of multiple methods to correspond with the complexity of research investigations will allow the apprehension of the different aspects involved in the constitution of the object under investigation. The concern is about the adoption of more and newer methodologies in order to better explore the object of study and how rigorous the use of those methodologies. The concern with more methods or more methodological rigor in a discipline is not ill-placed but it can disguise an absence of theoretical elaboration (Elejabarrieta 1990). As Baskerville (1996) points out, it is like "leaning against the lamppost for support rather than for illumination." While adopting new methodologies may contribute to the general development of the field, they are still used as a "comfort factor" to reassure the participants that proper practices are being followed to cope with the complexity associated with the field.

In a sense, this "need" of using more and "better accurate" methods in order to develop the field mirrors the Enlightenment notion of human betterment developed in social sciences, that with improved knowledge about our world (or about the object of study) and increased abilities to make rational decisions (on which is the best method), we will be able to design a world fit to live in.

\section{STARTING POINT OF METHODOLOGICAL CHOICE}

Historically, information systems research inherited the natural sciences paradigm (Mumford 1991) and, as a consequence, there are a number of underlying problems associated with information systems research (Cooper 1988). The major criticism in the past was that research tends to be dominated by scientific approaches (Nissen 1985; Mumford 1991). The models borrowed from natural sciences, suited to science laboratories, were transferred directly to information systems (Galliers and Land 1987) in an attempt to gain recognition and legitimization as a research area (Backhouse, Liebenau and Land 1991). However, they have proven to be "almost always doomed to fail" (Galliers and Land 1987). 
This background was borne out of the fact that information systems as a field has its origins in business schools in North America, where there has always been a tradition of functionalist and positivist approach (Orlikowski 1991). Promotion and tenure, which concerns a researcher's career, has a formula which is entrenched in doing the right type of research and publishing in the right type of journals. Academic respectability implies an approach to treat research as a science, with much of the effort placed on laboratory-based experimentation or on field surveys (Vogel and Wetherbe 1984). This seems to be "part of the American system of academic statuses" (Kling 1991, pp 738), and as a consequence, has contributed to the deeply rooted positivistic tradition in information systems research. Another example of this kind of institutional constraint is the doctoral program that follows the American model. There is certainly a divide between America and Europe in terms of the emphasis on traditional research methods in the doctoral curriculum. Much debates have surfaced about the virtues and shortcomings of this model.

However, the 1984 conference on qualitative research - precursor to the 1990 conference in Copenhagen - questioned the traditional approaches to research and criticized the so-called scientific method not only for its emphasis on quantification but also for the commitment among some researchers to a narrow paradigm that "assumes away much of the richness and complexity of information systems"(Weill and Olson 1989). As a result, we are beginning to see research that covers other areas of the information systems spectrum, from purely technical perspectives of systems design and implementation, to social perspectives of the structural and social consequences of information systems at the individual, organizational, and societal levels. The growing recognition and popularity of the information systems field as multidisciplinary within the social sciences and the humanities (Olaisen 1991) has opened the doors for the softer approaches (or qualitative approaches) and the use of methodologies imported from those fields. Currently, the field is still at the theory-building stage (Madon 1994), and the objective seems to be a search for increased understanding of the information systems phenomena in order to strengthen its theoretical base.

It can be said that there is an attempt to change paradigms, to perceive information systems not as a field that covers only the technical and measurable aspects but also the context within which the information system is being developed. Researchers in the field have started to rely on other disciplines from the social sciences to throw light on the problems faced by those designing and implementing information systems in a variety of organizational contexts (Backhouse, Liebenau and Land 1991). This involves being able to interpret or decipher the social phenomenon's basic characteristics. The social sciences may help in this endeavor since they have developed ways of seeing (or creatively discovering) some of those characteristics in a meaningful manner (Alvesson 1995).

However, its uptake in mainstream information systems research is scarce, or somehow misguided. So far, research in information systems is synonymous with the study of advanced quantitative procedures, with the emphasis on the development of 
a methodology scholar expertly versed in the knowledge and use of such procedures (Olaisen 1991). Alternative approaches such as action research, critical research, interpretivism and semiotics are rare.

The main criticism against traditional methods in favor of methodological pluralism and alternative approaches is that the research problems are looked at using the scientific paradigm as a base (Klein and Lyytinen 1985). Methodological bias in research has been reported in the information systems literature, between $50 \%$ and $90 \%$ of published material uses only three methods (laboratory experimentation, surveys and case studies) (Cash and Nunamaker 1989, 1990, 1991; Orlikowski and Baroudi 1990; Vogel and Wetherbe 1984). This led Klein, Hirschheim and Nissen to comment that "the most commonly held attitude in the information systems research community is not methodological pluralism, but the belief in the supremacy of a particular set of methodological postulates favoring certain methods and discriminating against others."

Morgan and Smircich (1980) propose that we look at other research modes for established frameworks of observation that can offer a unique range of insights unobtainable by existing methods, such as one that constitutes a specific hermeneutic mode located at the subjective end of the spectrum. However as Mumford (1991) quite rightly pointed out, we should avoid creating a situation whereby researchers either take the quantification route for its own sake, or undertake qualitative research simply to avoid handling numerical data.

This often opens up the debate on quantitative methods versus qualitative methods. Such debates have been at the center of much controversy in both the social and the natural sciences. Most of the time the discussion equates qualitative methodologies with positivistic postulates and qualitative methods as the monopoly of those who criticize those methods. In our view, this is an inadequate way of discussing the issue. The relationship between qualitative and quantitative is not a static one. Frequently, quantity and quality feed back into one another. The chasm between quantitative and qualitative techniques seems to be associated with a tradition of conducting research where the imperative of measurement displaced a concern with theory. The content of theoretical presuppositions can remain unclear under the formulation of hypothesis that, through sophisticated statistical methods, acquire the value of scientific findings. There is no doubt that those practices should be criticized, but the critique should not be out of focus.

Quantitative techniques have been extremely useful in identifying specific phenomena. Moreover there will always be research that relies on a heavy emphasis on use of statistical analysis, with the consequent need for exact measurement of the factors being studied. The question is not whether quantitative techniques can offer the researchers what qualitative techniques cannot and vice versa, but rather on the theoretical and philosophical assumptions that guide the research and therefore determine which methodology one uses. We argue that it is necessary to qualify the use of specific techniques in both the underlying assumptions guiding the research and in the theoretical framework. 


\section{THE OBJECT OF STUDY}

As within many other fields, the origins of the methodological debate in information systems can be found in the difficulties encountered in identifying the object of study (Kuutti 1996). Nissen, Klein and Hirschheim point out that the discussion should be centered around two basic issues: "i) the nature of what is investigated (ontology) and ii) the nature of human knowledge and understanding that can possibly be acquired through different types of research and the appropriateness of the methods of investigation (epistemology)." These two issues may be distinct but in our view they are nevertheless interrelated.

Information systems research has been said to be about the study of improving the effectiveness of information systems design, implementation and use in organizations, and to assess their impact on individuals, organizations and society at large (Keen 1987; Baskerville and Wood-Harper 1996; Galliers and Land 1987). As a highly applied field, it covers a broad spectrum, from practice-biased disciplines such as engineering and management, to soft disciplines such as psychology and sociology (Galliers and Land,1987; Banville and Landry 1989; Achterberg, Van Es and Heng 1991; Baskerville and Wood-Harper 1996).

We can hardly talk about the field as a paradigm in the commonly accepted sense of the concept: that is to say, a theoretically well-structured, broad and extensive research orientation, with a common view of the world, a methodological approach, definition of the research object and common theoretical ancestors and sources of inspiration (Kuhn 1970). Instead, the research field is characterized by a multitude of views and perspectives. According to an IFIP WG8.2 survey carried out in 1986 (quoted in Nissen, Klein and Hirschheim 1991), there are as many as thirty-two reference disciplines involved in information systems.

This broad spectrum creates problems when it comes to a homogeneous or even coherent definition of what information systems as a discipline should be studying. Is the object of research in information systems of a technological or a social nature? Is it the organization, an information system or a social system? As Kuutti asks, "If an organization is too broad and vague, an information system too narrow, and a social system too hazy and one-sided, then what is it that we are actually going to analyze and change?"

We believe that there is a need to bridge the analytical split between human and non-human, organizational life and the information system implemented or developed within the organization. The critical issue to be remembered in doing information systems research in organizations is that the world is composed of hybrids rather than discrete elements, either social or non-social (Grint, Case and Willcocks 1996). There is no condition where humans exist but in networks with humans and non-humans. It is the network of ideas, machines and people developed through an accommodation to each other that should be the focus of our inquiries (Latour 1988). In epistemological terms, to focus on those hybrids instead of discrete elements, run counter to the analytic position set up under the rules of the enlightenment and posit formidable 
problems of analysis. Our understandings are posed mainly between people and/or things but not on the agglomerations.

Consequently, the tradition in research, has been that one specific effect of one variable can be readily assessed. Therefore, it has been assumed that because we can assess the capacity of the technology, it is possible by the same means to assess its effects upon the organization or the human beings using it. The avoidance of studying single variables can actually help to obtain a more accurate understanding of the effects of technology if the focus is on the total situation instead: the mix of variables, including new technology, that comes together and interacts to produce certain consequences (Mumford 1987). Furthermore, even though it may be possible to measure and grasp the objective side of technology, it is still necessary to remain subjective on the human element. If the analysis is to be focused on the result of interactions between the network of human and non-human within the context of organization (Grint, Case and Willcocks 1996), we will need to take into account not only the objective, visible and measurable factors but also the changing environment in organizations and their dynamic and symbolic features, as well as the subjective or symbolic processes inherent in the process of doing information systems research (Zuboff 1996).

\section{QUALITATIVE RESEARCH IN INFORMATION SYSTEMS}

There is a push for more qualitative research, as witnessed by the success of the Orlikowski's (1993) employment of grounded theory and the forthcoming special edition of MIS Quarterly on intensive research. What exactly is qualitative research? Does the use of recognized qualitative methods qualify as qualitative research?

According to Van Maanen (1979, p. 520),

The label qualitative methods has no precise meaning in any of the social sciences. It is at best an umbrella term covering an array of interpretative techniques which seek to describe, decode, translate and otherwise come to terms with the meaning, not the frequency, of certain more or less naturally occurring phenomena in the social world.

Qualitative research has been defined in many ways and means different things to different people. Essentially, it is both a certain commitment to some versions of the naturalistic or interpretative approaches to its subject matter, and an ongoing critique of the politics and methods of positivism. Qualitative implies an emphasis on the processes and meanings that are not examined or measured in terms of quantity, amount, intensity or frequency.

Spielberg (1972) argues that using quantitative or qualitative methods of analysis implies a different perspective on human interaction and behaviour. The quantitative approach implies that there is an objective truth existing in the outside world which can be revealed through the use of the scientific method of measuring relationships between different variables systematically and statistically. The concern in this 
methodology is essentially that the measurements are reliable, valid and generalizable in their predictions of cause and effect. On the other hand, qualitative techniques emerging from phenomenology and interpretative paradigms emphasise a constructive approach where there is no clear-cut objectivity or reality. Social life is perceived as emerging from the shared creativity of individuals (Filstead 1978). The use of qualitative research stresses this socially constructed nature of reality, the intimate relationship between the researcher and what is being explored and the situational constraints which shape the process. Whereas in the positivistic approach, theory is deduced by testing hypothesis, in the phenomenological approach, theory is generated from the data collected, thus, it is grounded in the data (Glaser and Strauss 1967).

Qualitative research is also multi-method in focus, usually the choice of which methods to use or tools to employ is not decided in advance. The choice of research practices depends upon the questions that are asked, and the questions depend on their context (Nelson, Treichler and Grossberg 1992). Therefore, as a contrast with quantitative methods of research, the use of a qualitative framework is unlikely to impose restrictive a priori classifications in the collection of the data. Research is less driven by the testing of a specific hypotheses and categorical frameworks and more concerned with emergent themes and idiographic discussions. As a result, qualitative researchers are more likely to be aware of (and feel the need to explain) the epistemological stance they are taking, whereas few researchers working on the positivist tradition feel the need to do so. In the latter case, the research process becomes normative; it is usually the way research "is done."

However, the upshot in qualitative research is that qualitative researchers might find themselves explaining the paradigm they are using in terms of a paradigm they are not using, thus explaining the use of an interpretative approach in terms of a quantitative one using positivist terms such as reliability, generalizability and validity. The use of alternative approaches such as more qualitative methods in information systems research is therefore beset with the question of not achieving a complete shift in paradigms.

Toraskar (1991), for instance, utilized a field study approach via in-depth personal interviews to evaluate a class of decision support systems from an organizational and user oriented perspective. In his research, he had adopted grounded theory (Glaser and Strauss 1967) approach to the data analysis, where he claimed to be well suited for analyzing the vast amount of qualitative data generated through field-study. In his conclusion, he said that "the research strategy and the methods used here cannot be expected to offer the same degree of precision and reliability of results as the traditional causal-mechanistic methods" and that there is a "need for greater precision in research." It begs the question why he acknowledges the above as limitations of qualitative research, running contrary to what it is all about (see Glaser and Strauss 1967 and Strauss and Corbin 1990).

Calloway and Ariav (1991) also use grounded theory to interpret data gathered from studying the relationships of developers with their tools. They utilize exploratory studies, which are often used to generate hypotheses that can be subjected to quantita- 
tive methods, and their objective was to fashion a precise methodology that could be used elsewhere. Again, the opportunity is missed to use qualitative methods the way they were intended to be used.

Another example is case studies research, which has become popular and acceptable, due in part to the work of authors like Yin (1994), which simply treats it as another functionalist research approach (cf. Burrell and Morgan 1979; Lee 1989 and Galliers 1991). This is particularly evident in Lee's utilization of case studies to show how controlled observations and deductions, replicability, and generalizability can be achieved to test hypotheses. His objective was to satisfy the standards of the natural science model of scientific research.

In the examples given above, the objectives of the authors are admirable. But is not this a case of using qualitative methods in a quantitative fashion? The authors tried to explain the use of an interpretative approach in terms of a quantitative one, yielding to a tendency to apply directly in qualitative research the methods developed to assess reliability and validity in quantitative research (Flick 1992).

We acknowledge that the problem of validity has become increasingly important in research processes dealing with qualitative methods. The discussion of credibility and of generalizing data increases along with the use of qualitative methods. One concern of quantitative research is that the measures used will produce the same results when applied to the same subjects by different researchers: "The same 'yardstick' applied to the same individual or object in the same way should yield the same value from moment to moment, provided that the thing measured has itself not changed in the meantime" (Guildford and Fruchter 1978, p. 407), for the characteristics of the researcher to influence the way in which subjects respond to the instruments in a research process would endanger the reliability of the research. Qualitative research, on the other hand, seeks to describe and understand how people make sense of their world and, as such, does not require researchers to strive for this kind of objectivity or to distance themselves from research participants. Indeed, to do so would make qualitative research impossible, as the researcher's subjectivity is an essential part of the research process.

This does not mean that in interpreting qualitative data the issue of possible researcher bias should be ignored. We consider it just as important as in quantitative research that the interpretations are not a simple product of the researcher's biases and prejudices. A first step to revise and improve this is the recognition of the researcher's self consciousness of being an actor in the research process. This leads us to the issue of validity. In quantitative research, a valid instrument is one which actually measures what it claims to measure. Similarly, in qualitative research, a study is said to be valid if it truly examines the topic which it claims to have examined. It could be said then that, in essence, the concept of validity is the same in both research approaches. Where the approaches differ is in the quantitative research's notion of validity, which is centered on the methods, i.e., the validity of the items in a questionnaire as opposed to the focus on the validity of interpretations. Thus, whether a researcher's conclusion that $\mathrm{X}$ is the main theme to emerge from the analysis is valid. 
There is a considerable debate of what constitutes good interpretation in qualitative research (for a detailed account of the different positions, see Hammersley 1992). Our position is that, as long as we try to base our claims of social processes on data of any kind, we must have a logic for assessing and communicating the interactive process through which we, as researchers, have acquired the research experience and information. If, as we claim, we want to include in our analysis and to expand our understanding of the "detailed means through which human beings engage in meaningful action and create a world of their own or one which is shared with others" (Morgan 1983, p. 397), we need to recognize that "insufficient attention has yet to be devoted to evolving criteria for assessing the general quality and rigour of interpretative research" (Morgan 1983, p. 399).

In information systems, case studies have been evaluated in order to assess their rigour and validity (Yin 1994; Benbasat, Goldstein and Mead 1987; Walsham 1993, 1995). For example, while Lee's work provided the principles and guidelines for case studies by analyzing them from the philosophical perspective of positivism, Klein and Myers (1995) undertook a similar endeavour from the philosophical perspective of hermeneutics for the interpretive field research, in which they propose a systematic list of principles for conducting and evaluating interpretive research.

Qualitative researchers propose the triangulation of methods as one way to achieve this rigour. However, the use of multiple methods or triangulation reflects an attempt to secure an in-depth understanding of the phenomena in question. Triangulation is not a tool or strategy of validation but rather an alternative to validation. The combination of multiple perspectives, methods, empirical materials and observations in a study is, therefore, best understood as a strategy that can add rigour, breath and depth to any investigation (Flick 1992).

Researchers may choose to use different kinds of materials as their data, either quantifiable or of a qualitative nature, but that does not change the fact that the researchers are observers of a world in which they also participate. The research is mediated by a concrete framework of symbols and cultural meanings given by aspects of the life story that the researcher brings to the observational setting. In this sense, all research methods are "essentially qualitative and are for that matter essentially objective; the use of quantitative data or mathematical procedures does not eliminate the intersubjective element that underlies social research" (Vidich and Lyman 1994). Thus, the researcher always remains at the center of the research process.

The question about relying on and emphasizing on quantification was posed to the Information Systems Doctoral Mailing List discussion (MISDOC-L 1996) by one of the authors of this paper to get a feel of how doctoral students perceived and are affected by any of the research traditions. Surprisingly, there was no argument about the use of both quantitative and qualitative methods. Indeed it was encouraging to hear comments such as "regardless of whether quantitative or qualitative methods are used for a research project, I think the qualitative grounded theory approach is a critical research tool. In social science, even a large effect size is still small in abso- 
lute [terms]. One should use [the] qualitative approach to understand the context and complexity of the social phenomena in question" (a respondent).

Even the advocation for qualitative research to be used only to supplement quantitative methods is a non-issue. However, there was still a major problem in employing qualitative methods in research. Despite a recognition for its role, the problem stems from the fact that, in practice, quantitative research pays off more. "I cannot help focusing more on quantitative data consciously" (a respondent). In this respondent's case, he has used both quantitative and qualitative methods for his dissertation, but found that researchers and practitioners are more impressed that he surveyed 20,000 households than anything he found in in-depth interviews: "I think it [qualitative methods] provides more 'human-touch' to the study. Even when I analyze questionnaire data, I keep thinking about the people I interviewed. Their voice, their life stories, etc., remind me that I am studying real people and the responses on questionnaires are not just numbers, but it represents thoughts, opinions, and feelings of real people."

With the recognition of qualitative methods in the information systems field, there are now new research methods (Mumford et al. 1985) to help access the symbolically structured object domain of inquiry that were not developed in the natural sciences. In this light, qualitative research has now gained in-roads into the information systems research arena. Nonetheless, despite recognizing the limitations of traditional scientific methods and the negativity associated with this scientific tradition, the irony is that it still dominates all research done in the field (Klein and Lyytinen 1985). Galliers and Land pointed out that $85 \%$ of published IS research undertaken by leading US institutions is of the traditional kind.

Such institutional barriers to research practices have been recognized in the past (Orlikowski 1991). The use of the tools for research unfortunately still end up being a political choice translatable to economics dollars and cents. On a positive note, we know it will be a slow and even long process, but at least the wheels have been set in motion, as evidenced by the theme of this conference and the works of Myers, Klein and others.

\section{RESEARCHER'S SUBJECTIVITY AS A STRENGTH}

Using qualitative methods in the research process is a reflexive activity, constantly informing the researcher's actions. The tools of interpretation are learned through experience (see the debate between Boland and Jonsson in Nissen, Klein and Hirschheim). A researcher's subjectivity enables penetration of the fronts individuals and groups represent which, in turn, permits deeper understanding of actors' perspectives and ways of living. It is a myth that the researcher can claim value neutrality in social research. Even the way we represent the research data is a political choice (Said 1989). 
Qualitative methods allow for that subjectivity in the research process and that is clearly their advantage. Within the qualitative research tradition, there is an acceptance of the inherent subjectivity of the research endeavour (Bryman 1988). There are the participant's perspectives on and the interpretations of the situation which are of value in understanding behaviour, therefore a search of objectivity in this type of research will be somehow misguided. In other words, verification cannot be considered to be of decisive significance in assessing the value of the research (Alvesson 1995). But if researchers in information systems still insist in the objectivity of the research process, then according to Mumford (1987), "research must be objective, but it can never be value-free."

This opens the debate between the objective knowledge or subjective knowledge in the research process. The claim for objectivity is an old and debatable issue in the social sciences. It is more than a technical question. It relates to the very nature of the relationship between the elements of the research process, namely the object, the researcher, the subjects (actors) and the results. In information systems, this ontological distinction between objectivism and subjectivism pervades its development methods. When combined with epistemological issues, this distinction leads again to a seemingly implacable dualism of scienticism and interpretativism.

However, the object of investigation is a subjective domain comprising the subjects of social life. The researcher is not usually separated from the object of inquiry but rather exposed to the very same conditions which gave rise to the problem under inquiry (Thompson 1990). There is a relation of potential exchange between the outcome of the social inquiry and the reality from which the outcome emerges. Human beings know and undergo the effects of knowledge they develop about themselves. Objectivity in social sciences assumes a meaning only in relation to a subjective domain which confirms and supports the claim of an objective reality.

As Latour (quoted in Vidgen and McMaster 1996) argues,

The separation of an objective and given natural world from a sociallyconstructed social world...contains a paradox in so far as it exposes separation of natural and social worlds while relying upon their inseparability for success.... [As such, we do not need to] attach our explanations to the two pure forms know as the object or subject/society, because these are, on the contrary, partial and purified results of the central practice that is our sole concern.

Acknowledging the inherent subjectivity of the research process implies a reconciliation of subject and object, which takes place through a dialectical logic. The knowledge of the world and the knowledge of one-self are co-constitutive of each other rather than as separate categories. The empirical datum and the human mind co-determine each other in such a way that both are transformed through the very activity that their encounter engenders. "It is neither subjective, nor 'objective knowledge'. It is knowledge based on interaction between the knowing subject and the object of its knowledge" (Markova 1982, p. 112). 


\section{RESEARCH AS A CULTURAL EXPERIENCE}

Because of the stress on using qualitative methods in natural settings, Kirk and Miller (1986) suggest that qualitative researchers are engaged in interacting with people in their own language and in their own terms. There is a shift in the description of the people involved in the study as participants and not as subjects. The agreements between the researcher and the participants in the study about the meaning in particular situations or events being studied has led in some cases to more participative research situations. There is not only a recognition of the autonomy of the participant in the research but also a recognition of the role the researcher plays in the study. This is one of the main thrusts of action research (Antill 1985; Wood-Harper 1985; Baskerville and Wood-Harper 1996). Rather than being an involved bystander observing the organizational action, the researcher has an impact on the behaviour and expectations of those around (Cassell and Symon 1994).

Westrup (1996, p. 167) refers to system developers as constituting the organizations they seek to develop information systems for and that what will be fruitful is investigation of the practices of the developers themselves. Likewise, systems analysts are not simply engaged in analyzing an organization (using traditional or refined tools) but use analysis as a resource to construct a representation of the organization that requires the use of an information system.

Indeed, it would be absurd to assume the researchers themselves operate free of a cultural context of any kind; rather it is too obvious that we, too, belong to various thought worlds. Paradigms reflect fashions in the professional time-collective, but the space-collective also leaves its mark. "It is an illusion that we can escape our thought world and immerse ourselves, naked of prejudice into another one" (CzarniawskaJoerges 1991, p. 295). The best we can try to do is to expand our thought world by understanding the possibility of other worlds or "sub-universes of meaning" (Berger and Luckmann 1966).

For instance, Madon says that research into the organizational context of information systems reveals a substantial difference between developing and industrialised countries. In her investigation into the adoption of information systems and technology transfer in India, she found that it is not a matter of replicating the institutions and approaches of the developed countries, but of adapting them to the priorities and contextual characteristics of the developing country in question, in terms of its lack of resources, infrastructure, and the constraints imposed by the social and political context (Felts 1987; Bell and Sheppard 1988; Madon 1994). Hammersley and Atkinson (1983) also support this view:

We are part of the social world we study....This is not a matter of methodological commitment, it is an existential fact. There is no way in which we can escape the social world in order to study it; nor fortunately, is that necessary. We cannot avoid relying on "common-sense" knowledge nor, often, can we avoid having an effect on the social phenomena we study. 
Research, therefore, should be regarded as the activity where the researcher's subjectivity has an unavoidable impact (Alvesson 1995). The observations of the researcher are always guided by world images that determine which data are salient and which are not. Thus, there are no ready-made data waiting for the researcher to be collected, but rather a prestructured selection of the data to be gathered which will influence their later interpretation and understanding. The development of knowledge in a discipline cannot be regarded only as based on epistemological or methodological concerns but also based on the researcher's views and opinions. An act of attention to one object rather than another can reveal a dimension of the researcher's commitment to concrete values, as well as his or her own value-laden interests. Data as such is the result of and is principally determined by interpretation and theory.

As such, research activity should consist of abandoning the taken-for-grantedness of the research context in order to problematize the practices of the actors performing in such a context. It soon becomes clear that this is not a one-way process, as the researcher's practices become problematized in turn. And if the researcher takes a neutral stance by "play(ing) naive we can get acceptance in strange worlds but probably wouldn't understand them (playing naive requires a non-problematic stance towards what is happening taken for granted what it is)" (Czarniawska-Joerges 1991). If we want the understanding, we must ask by posing questions, we problematize by problematizing, otherwise we will reveal ourselves as not really belonging.

Even writing the reports or descriptions becomes an interpretative endeavour as researchers' ideas rarely if ever occur in a systematic, structured way. As Geertz (1988) says, the descriptions filtered through the researcher are second or third order fictions. Clifford and Marcus (1986) argue that the various blindness, evasions, and fictions that were created in order to produce ethnographic insights essentially require new vocabularies and new modes for describing the social and cultural worlds being studied. Stated simply, there is no object of study "out there" to be accurately represented by observers; rather, the observer creates fictions in the process of investigation (Riley 1991).

Methodologies inevitably embed the creator's philosophical paradigms. According to Polanyi (1964), the researcher has the perogative to reserve judgement on finding a good problem, and of the surmises to pursue it, as well as the recognition of a discovery that solves it. This is inspite of following the rules of a scientific inquiry:

In each such decision the researcher may rely on the support of a rule; but he is then selecting a rule that applies to the case, much as the golfer chooses a suitable club for his next stroke. His choosing will depend on his background and training - and his world view.

In summary, the research process should not be thought of as following an explicit bureaucratic procedure and a clear account of the methods employed, but rather one that is based more on being aware of theory and meta-theory, continuously reflecting on the current position and future developments when reading and conducting empirical work, open to ideas and suggestions. The data is as much an artificial construction as it is a reflection of empirical reality (Alvesson 1995). 
Using qualitative methods implies that more attention should be paid not only to multiple narratives that give voice to and allow the construction of multiple worlds, but also to the role of the researcher, of his understanding, insights, experiences, interpretations, etc. A good researcher will be one who can bring such subjectivity to the fore, backed with quality arguments rather than just a display of statistical exactness, precision or confidence.

Multiple narratives will not give us any one representation but they may "give us more interesting ways to think about the organization, ethics, and aesthetics of work than the search for such true systems has" (Boland and Schultze 1996, p. 332). However, as we have seen so far, the narrative in information systems is one of a progress toward clarity, simplicity and purity. Boland and Schultze blame the aura that surrounds information technology, as if it has some magical power to make clear what is blurred and purify what is contaminated. As a result, despite the efforts to date in using qualitative methods, information systems still tend to be fixated by data and a quest for quantification.

\section{CONCLUSION}

We would like to reiterate that methodological questions do not relate simply to technical procedures and are not a matter of either applying a quantitative or qualitative method. Although the debate is centred around the presumed opposition of qualitative versus quantitative methodologies, it seems that such an opposition is entirely false and does not touch upon the fundamental issues. Methodology relates and actually depends upon theoretical issues which in turn are bound to philosophical conceptions. It is the close connection between the three that guides research options. Therefore, we have tried to challenge the assumption that just an increased adoption of methodologies would help address the problems inherent in information systems research.

In the final analysis, there is probably no such thing as a single, simple and clear road regarding research methods in information systems. As Westrup (1996, p. 170) stated, "adopting a [new approach] to systems development may lead to several advantages though it is unlikely to afford the luxury of yet a better technique of systems development." A better approach would be to use them as suggested frameworks, or guidelines, rather than as dogma (Baskerville 1996). As for doing qualitative research in information systems, that will be the day when we start using qualitative methods in a qualitative way, the day when we dare to be subjective.

\section{ACKNOWLEDGMENTS}

The authors would like to thank Professor Jonathan Liebenau for his encouragement and guidance on our work, and also to the different blind reviewers for their excellent and detailed critique of our paper. We hope that we have done justice to them all. 


\section{REFERENCES}

Acterberg, J. S.; van Es, G. A.; and Heng, M. S. H. (1991). "Information Systems Research in the Postmodern Period." In H-E. Nissen, H. K. Klein, and R. Hirschheim (Editors), The Information Systems Research Arena of the 90s, Challenges, Perceptions and Alternative Approaches. Amsterdam: North-Holland.

Alvesson, M. (1995). Management of Knowledge-Intensive Companies. Berlin: De Gruyter.

Antill, L. (1985). "Selection of a Research Method.” In E. Mumford, R. Hirschheim, G. Fitzgerald, and A. T. Wood-Harper (Editors), Research Methods in Information Systems. Amsterdam: North-Holland.

Backhouse, J.; Liebenau, J.; and Land, F. (1991). “On the Discipline of Information Systems." Journal of Information Systems, Volume 1, pp. 19-27.

Banville, C., and Landry, M. (1989). "Can the Field of MIS be Disciplined?" Communications of the ACM, Volume 32, pp. 48-61.

Baskerville, R. (1996). "The Second-Order Security Dilemma." In W. J. Orlikowski, G. Walsham, M. R. Jones, and J. I. DeGross (Editors), Information Technology and Changes in Organizational Work. London: Chapman and Hall.

Baskerville, R. L., and Wood-Harper, A. T. (1996). "A Critical Perspective on Action Research as a Method for Information Systems Research." Journal of Information Technology, Volume 11.

Bell, S., and Sheppard, I. (1988). Application of a Systems Development Methodology in Less Developed Countries. Norwich, England: University of East Anglia.

Benbasat, I.; Goldstein, D. K.; and Mead, M. (1987). "The Case Research Strategy in Studies of Information Systems." MIS Quarterly, Volume 11, Number 3, September, pp. 369-386.

Berger, P., and Luckmann, T. (1966). The Social Construction of Reality. London: Penguin.

Bikson, T. (1991). "Relevance versus Rigor in Information Systems Research: An Issue of Quality." Panel Discussion chaired by J. A. Turner. In H-E. Nissen, H. K. Klein, and R. Hirschheim (Editors), Information Systems Research: Contemporary Approaches and Emergent Traditions. Amsterdam: North-Holland.

Boland, R. J, and Schultze, U. (1996). "From Work to Activiy: Technology and the Narrative of Progress." In W. J. Orlikowski, G. Walsham, M. R. Jones, and J. I. DeGross (Editors), Information Technology and Changes in Organizational Work. London: Chapman and Hall.

Bryman, A. (1988). Quantity and Quality in Social Research. London: Unwin Hyman.

Burrell, G., and Morgan, G. (1979). Sociological Paradigms and Organizational Analysis. London: Heinemann.

Calloway, L. J., and Ariav, G. (1991). "Developing and Using a Qualitative Methodology to Study Relationships among Designers and Tools.” In H-E. Nissen, H. K. 
Klein and R. Hirschheim (Editors), Information Systems Research: Contemporary Approaches and Emergent Traditions. Amsterdam: North-Holland.

Cash, J., and Nunamaker, J. (1989). The Information Systems Research Challenge, Vol I: Qualitative Research Methods. Boston: Harvard Business School Press. Cash, J., and Nunamaker, J. (1990). The Information Systems Research Challenge, Vol II: Qualitative Research Methods. Boston: Harvard Business School Press. Cash, J., and Nunamaker, J. (1991). The Information Systems Research Challenge, Vol III: Qualitative Research Methods. Boston: Harvard Business School Press. Cassell, C., and Symon, G. (1994). Qualitative Methods in Organizational Research. London: Sage.

Clifford, J., and Marcus, G. E. (1986). Writing Culture: The Poetics and Politics of Ethnography. Berkeley: University of California Press.

Cooper, R. (1988). "Review of Management Information Systems Research: A Management Support Emphasis." Information Processing and Management, Volume 24, Number 1, pp. 73-102.

Czarniawska-Joerges, B. (1991). "Culture is a Medium of Life." In P. J. Frost, L. F. Moore, M. R. Louis, C. C. Lundberg and J. Martin (Editors), Reframing Organizational Culture. London: Sage.

Danzinger, K. (1979). "The Positivistic Repudiation of Wundt." Journal of the History of the Behavioral Sciences, Volume 15, pp. 205-230.

Elejabarrieta, F. (1990). "La Rigurosidad metodologica y la precariedad teorica en Psicologia Social." Quaderns de Psicologia, Volume 10, pp. 143-160.

Felts, R. A. (1987). The Development of Information Systems in the Third World. M.Sc. Dissertation, London School of Economics.

Filstead, W. J. (1978). "Qualitative Methods: A Needed Perspective in Evaluation Research." In T. D. Cook and C. S. Reichardt (Editors), Qualitative and Quantitative Methods in Evaluation Research. Beverley Hills, California: Sage.

Flick, U. (1992). "Triangulation Revisited: Strategy of Validation or Alternative?" Journal of the Theory of Social Behavior, Volume 22, pp. 175-198.

Galliers, R. D. (1991). "Choosing Appropriate Information Systems Research Approaches: A Revised Taxonomy." In H-E. Nissen, H. K. Klein and R. Hirschheim (Editors), Information Systems Research: Contemporary Approaches and Emergent Traditions. Amsterdam: North-Holland.

Galliers, R. D., and Land, F. L. (1987). "Choosing Appropriate Information Systems Research Methodologies." Communications of the ACM, Volume 30, Number 11, pp. 900-902.

Geertz, C. (1988). Works and Lives: The Anthropologist as Author. Stanford, California: California University Press.

Glaser, B., and Strauss, A. L. (1967). The Discovery of Grounded Theory: Strategies for Qualitative Research. Chicago: Aldine.

Grint, K.; Case, P.; and Willcocks, L. (1996). "Business Process Reengineering Reappraised: The Politics and Technology of Forgetting." In W. J. Orlikowski, 
G. Walsham, M. R. Jones, and J .I. DeGross (Editors), Information Technology and Changes in Organizational Work. London: Chapman and Hall.

Guerreiro-Ramos, A. (1981). The New Science of Organization. Toronto: University of Toronto Press.

Guilford, J. P., and Fruchter, B. (1978). Fundamental Statistics in Psychology and Education. London: McGraw-Hill.

Hammersly, M. (1992). What is Wrong with Ethnography? Methodological Explorations. London: Routledge.

Hammersly, M., and Atkinson, P. (1983). Ethnography Principles in Practice. London: Routledge.

Keen, P. G. W. (1987). "MIS Research: Current Status, Trends and Needs." In R. A. Buckingham, R. A. Hirschheim, F. F. Land and C. J. Tully (Editors), Information Systems Education: Recommendations and Implementation. Cambridge, England: University Press.

Kirk, J., and Miller, M. L. (1986). Reliability and Validity in Qualitative Research. Qualitative Research Methods Series, Volume 1. Beverley Hills, California: Sage.

Klein, H. K.; Hirschheim, R.; and Nissen, H-E. (1991). "A Pluralist Perspective of the Information Systems Research Arena." In H-E. Nissen, H. K. Klein and R. Hirschheim (Editors), Information Systems Research: Contemporary Approaches and Emergent Traditions. Amsterdam: North-Holland.

Klein, H. K., and Lyytinen, K. (1985). "The Poverty of Scientism in Information Systems." In E. Mumford, R. Hirschheim, G. Fitzgerald and A. T.Wood-Harper (Editors), Research Methods in Information Systems. Amsterdam: North-Holland.

Klein, H. K., and Myers, M. D. (1995). "The Quality of Interpretive Research in Information Systems." Department of Management Science and Information Systems, University of Auckland, Working Paper No. 89, May.

Kling, R. (1991). "Social Analyses of Computing: Theoretical Perspectives in Recent Empirical Research." Computing Surveys, Volume 12, Number 1, pp. 61110.

Kuhn, T. S. (1970). The Structure of Scientific Revolutions. Chicago: University of Chicago Press.

Kuutti, K. (1996). "Debates in IS and CSCW Research: Anticpating System Design for Post-Fordist Work." In W. J. Orlikowski, G. Walsham, M. R. Jones, and J. I. DeGross (Editors), Information Technology and Changes in Organizational Work. London: Chapman and Hall.

Latour. B. (1988). "The Prince for Machines as Well as for Machinations." In B. Elliot (Editor), Technology and Social Processes. Edemburg: Edemburg University Press.

Lee, A. (1989). “A Scientific Methodology for MIS Case Studies.” MIS Quarterly, Volume 13, Number 1, pp. 33-50.

Madon, S. (1994). Designing Information Systems for Development Planning. Henley-on-Thames, England: Alfred Waller Ltd. 
Markova, I. (1982). Paradigms, Thought and Language. Chichester, England: John Wiley and Sons.

MISDOC-L (1995). IS Doctoral Mailing List. http://web.bu.edu:80/SMGMIS/ misdoc-1.

Morgan, G. (Editor) (1983). Beyond Method. Beverley Hills, California: Sage.

Morgan, G., and Smircich. L. (1980). "The Case for Qualititative Research." Academy of Management Review, Volume 5, Number 4, pp. 491-500.

Mumford, E. (1987). "Managerial Expert Systems and Organizational Change: Some Critical Research Issues." In R. J. Boland and R. A. Hirschheim (Editors), Critical Issues in Information Systems Research. Chichester, England: John Wiley \& Sons, pp. 135-156.

Mumford, E. (1991). "Information Systems Research-Leaking Craft or Visionary Vehicle?" In H. E. Nissen, H. K. Klein, and R. Hirschheim (Editors), Information Systems Research: Contemporary Approaches and Emergent Traditions. Amsterdam: North-Holland.

Mumford, E.; Hirschheim, R.; Fitzgerald, G.; and Wood-Harper, A. T. (Editors) (1985). Research Methods in Information Systems. Amsterdam: North-Holland.

Nelson, C.; Treichler, P. A.; and Grossberg, L. (1992). "Cultural Studies." In L. Grossberg, C. Nelson and P. A. Treichner (Editors), Cultural Studies. New York: Routledge.

Nissen, HE. (1985). "Acquiring Knowledge of Information Systems: Research in a Methodological Quagmire.” In E. Mumford, R. Hirschheim, G. Fitzgerald and A.T. Wood-Harper (Editors), Research Methods in Information Systems. Amsterdam: North-Holland, pp. 39-51.

Nissen, H-E., Klein, H. K.; and Hirschheim, R. (Editors) (1991). Information Systems Research: Contemporary Approaches and Emergent Traditions. Amsterdam: North-Holland.

Olaisen, J. (1991). "Pluralism or Positivistic Trivialism: Important Trends in Contemporary Philosophy of Science." In H-E. Nissen, H. K. Klein and R. Hirschheim (Editors), Information Systems Research: Contemporary Approaches and Emergent Traditions. Amsterdam: North-Holland.

Oppenheimer, J. R. (1954). “Analogy in Science.” American Psychologist, Volume 11, pp. 127-135.

Orlikowski, W. J. (1991). "Relevance versus Rigor in Information Systems Research: An Issue of Quality." Panel Discussion chaired by J. A. Turner. In H-E. Nissen, H. K. Klein, and R. Hirschheim (Editors), Information Systems Research: Contemporary Approaches and Emergent Traditions. Amsterdam: North-Holland.

Orlikowski, W. J. (1993). "CASE Tools as Organizational Change: Investigating Incremental and Radical Changes in Systems Development." MIS Quarterly, Volume 17, Number 3, pp. 309-450. 
Orlikowski, W. J., and Baroudi, J. (1990). "Studying Information Technology in Organizations: Research Approaches and Assumptions." Sloan Management School, Massachusetts Institute of Technology, Working Paper.

Polanyi, M. (1964). Science, Faith and Society: A Searching Examination of the Meaning and Nature of Scientific Inquiry. Chicago: University of Chicago Press. Preston, A. M. (1991). "The 'Problem' in and of Management Information Systems." Journal of Accounting, Management and Information Technology, Volume 1, Number 1, pp. 43-69.

Reed, M. (1985). Redirections in Organizational Analysis. London: Tavistock.

Riley, P. (1991). "Cornerville as Narration." In P. J. Frost, L. F. Moore, M. R. Louis, C. C. Lundberg and J. Martin (Editors), Reframing Organizational Culture. London: Sage.

Said, E. W. (1989). "Representing the Colonized: Anthopology's Interlocutors." Critical Inquiry, Volume 15, pp. 205-255.

Spielberg, H. (1972). Phenomenology in Psychology and Psychiatry: A Historical Introduction. Evanston, Illinois: Northwestern University Press.

Strauss, A., and Corbin, J. (1990). Basics of Qualitative Research: Grounded Theory Procedures and Techniques. London: Sage.

Thompson, J. B. (1990). Ideology and Modern Culture. Cambridge, England: Polity Press.

Toraskar, K. V. (1991). "How Managerial Users Evaluate Their Decision Support: A Grounded Theory Approach." In H-E. Nissen, H. K. Klein and R. Hirschheim (Editors), Information Systems Research: Contemporary Approaches and Emergent Traditions. Amsterdam: North-Holland.

Van Maanen, J. (1979). "Reclaiming Qualitative Methods for Organizational Research: A Preface." Administrative Science Quarterly, Volume 24, pp. 520-26.

Vidgen, R., and McMaster, T. (1996). "Black Boxes, Non-human Stakeholders and the Translation of IT Through Mediation." In W. J. Orlikowski, G. Walsham, M. R. Jones, and J. I. DeGross (Editors), Information Technology and Changes in Organizational Work. London: Chapman and Hall.

Vidich, A. J., and Lyman, S. M. (1994). "Qualitative Methods: Their History in Sociology and Anthropology." In N. K. Denzin and Y. S. Lincoln (Editors), Handbook of Qualitative Research. London: Sage.

Vogel, D. R., and Wetherbe, J. C. (1984). "MIS research: A Profile of Leading Journals and Universities." DataBase, Volume 16, Number 3.

Walsham, G. (1993). Interpreting Information Systems in Organizations. Chichester, England: Wiley.

Walsham, G. (1995). "Interpretive Case Studies in IS Research: Nature and Method." European Journal of Information Systems, Volume 4, pp. 74-81.

Weill, P., and Olson, M. H. (1989). "An Assessment of the Contingency Theory of Management Information Systems." Journal of Management Information Systems, Volume 6, Number 1, pp. 59-86. 
Westrup, C. (1996). "Transforming Organizations Through Systems Analysis: Developing New Techniques for Organizational Analysis in IS Development." In W. J. Orlikowski, G. Walsham, M. R. Jones, and J. I. DeGross (Editors), Information Technology and Changes in Organizational Work. London: Chapman and Hall.

Wood-Harper, A. T. (1985). "Research Methods in Information Systems: Using Action Research." In E. Mumford, R. Hirschheim, G. Fitzgerald and A. T. WoodHarper (Editors), Research Methods in Information Systems. Amsterdam: NorthHolland.

Yin, R. K. (1994). Case Study Research, Design and Methods, Second Edition. Newbury Park, California: Sage Publications.

Zuboff, S. (1996). "The Emperor's New Information Technology." In W. J. Orlikowski, G. Walsham, M. R. Jones, and J. I. DeGross (Editors), Information Technology and Changes in Organizational Work. London: Chapman and Hall.

\section{BIOGRAPHY}

Lucia Garcia is a Ph.D. candidate in the Social Psychology Department at the London School of Economics (LSE) working on Organizational and Cultural Change. She also teaches Organizational Psychology and Qualitative Research Methods at the Methodology Institute at LSE. She has participated in a number of research projects in Latin America and Eastern Europe regarding organizational transformation in those countries. Currently she is a Research Officer at LSE acting as coordinator for the WHO Healthy Cities Evaluation Project as well as for the US based SRDI Telecommunications Network. Her interests are mainly in organizational transformation from a social psychological perspective focusing on community building, inter- and intraorganizational networks and the role of telecommunications on the transformation process as well as in social research methods.

Freddie Quek is an Information Systems Manager at Electronic Press Ltd. (UK), which is the electronic publishing arm of the Current Science Group, a medical publishing company. He received a Masters of Science from the London School of Economics and is currently pursuing his Ph.D. in Information Systems at the same institution. He is the Professional Activities Division Editor of ISWorld Net, and the Editorial Director of Connect-World Latin America, a publication dedicated to the discussion of liberalization of telecommunications in Latin America. His current research interests include decision support systems, electronic publishing, databases, the use of web-based technologies to support collaborative work and liberalization of telecommunications. 